\title{
La reforma de la Iglesia en clave sinodal. Una agenda compleja y articulada
}

\author{
Carlos Schickendantz \\ CENTRO TEOLÓGICO MANUEL LARRAÍN \\ UNIVERSIDAD ALBERTO HURTADO \\ cschickend@uahurtado.cl
}

Resumen: En octubre de 2015 se realizó un seminario internacional sobre la reforma de la Iglesia en Roma, con la participación de treinta académicos y académicas pertenecientes a diversas disciplinas teológicas y provenientes de trece países. El objetivo del encuentro no se orientaba solo a discusiones teóricas sobre la reforma, sino que pretendía aportar un estado de la cuestión actualizado y ofrecer una serie de recomendaciones para la implementación práctica en el corto, en el mediano y en el largo plazo. El presente artículo saca a la luz algunas ideas centrales allí expuestas, formula opiniones sobre diversos aspectos de la reforma en curso e, incluso, aporta sugerencias precisas como algunas modificaciones en el Código de derecho canónico.

Palabras clave: Sinodalidad, colegialidad, papado, curia romana, iglesias locales

Abstract: An international Symposium on the reform of the Church was held in October 2015 in Rome, with the participation of thirty scholars from various theological disciplines coming from thirteen countries. The objective of the meeting was not only oriented to theoretical discussions about the reform, but rather aimed to provide an updated state of the issue and offer to a series of recommendations for its practical implementation in the short, medium and long term. This article brings to light some of the central ideas set out therein, formulates opinions on various aspects of the current reform, and even provides specific suggestions, such as some amendments to the Code of Canon Law.

Key words: Synodality, collegiality, papacy, Roman curia, local churches 


\section{INTRODUCCIÓN}

La noción de reforma se caracteriza tradicionalmente como "una mutatio in melius, es decir, el cambio como una supuesta mejora en el statu quo". Por tanto, una reforma eclesial puede designar procesos de muy diversa naturaleza, que incluyan los más variados aspectos de su organización y misión. Utilizada en sentido amplio la expresión puede incluir la renovación de toda la vida de la Iglesia, tanto la "renovación del espíritu", como la "reforma de la institución"2. Por lo tanto, cuando una contribución, libro o congreso se aboca a esta tarea -reforma de la Iglesia, reformas en la Iglesia- debe necesariamente delimitar su campo de trabajo y exponerse a la objeción que no ha tratado todos los asuntos, o que los ha considerado de una manera excesivamente breve o que, por el contrario, ha omitido aspectos que parecían esenciales. La temática, entonces, puede seguir diversos caminos.

En el mes de octubre de 2015 se realizó un seminario internacional sobre la reforma de la Iglesia en la sede de La Civiltà Cattolica, en Roma, con la participación de treinta académicos y académicas pertenecientes a diversas disciplinas teológicas (eclesiólogos, historiadores, canonistas, ecumenistas, pastoralistas) y a trece países distintos. El objetivo del encuentro no se orientaba solo a discusiones teóricas sobre la reforma, sino que, expresamente, pretendía aportar un estado de la cuestión actualizado sobre los distintos asuntos implicados y ofrecer una serie de recomendaciones para su implementación práctica. En setiembre de 2016 se han publicado en Italia, bajo la responsabilidad editorial de Antonio Spadaro y Carlos Galli, los materiales presentados y debatidos en ese evento. Mi objetivo en este artículo no es presentar dicho libro, sino sacar a la luz algunas ideas centrales allí expuestas, también deseo expresar mi opinión sobre diversos aspectos de la reforma en curso e, incluso, aportar sugerencias precisas a modo de ejemplo, como algunas modificaciones en el Código de derecho canónico actual.

Tres textos del volumen citado, en particular, ofrecen un marco adecuado para comprender la coyuntura en que se encuentra una agenda

\footnotetext{
1 J. O'MAlley, "La reforma nella vita della Chiesa. Il concilio di Trento e il Vaticano II", en A. SPADARO - C. M. GALLI (eds.), La reforma e le riforme nella Chiesa (Queriniana, Brescia 2016) 85-107, 85.

2 Cf. Y. Congar, "Renovación del espíritu y reforma de la institución”, en Concilium 73 (1972) 326-337.
} 
eclesial de transformaciones. El aporte de A. Spadaro brinda una buena reflexión que ayuda a explicar los pasos actuales de la reforma desde la peculiaridad de la personalidad humana y espiritual de Francisco, el obispo de Roma. La consideración del trasfondo ignaciano del estilo en curso es necesario para explicar mejor lo que se está desarrollando ante nuestros ojos ${ }^{3}$. El aporte personal de Carlos Galli refleja, desde otra perspectiva, ideas fundamentales que impulsan la renovación en ejecución: una reforma guiada por el paradigma de la conversión misionera a partir de la alegre novedad del Evangelio, de la ternura misericordiosa de Dios y de la teología conciliar del pueblo de Dios evangelizador ${ }^{4}$. Cada una de las palabras citadas está cargada de sentido. La exposición de Víctor Fernández complementa estas perspectivas poniendo de relieve otros aspectos centrales como, por ejemplo, la importante noción de autotrascendencia que está en la base del concepto de "salida de sî", misionero, que caracteriza la misma concepción de persona humana, debe determinar el perfil del creyente y la misma naturaleza de la comunidad eclesial como se ha plasmado en Evangelii gaudium. Se pone el acento sobre la vuelta a lo esencial: un "retorno al Evangelio", no a supuestos "valores innegociables" que oscurecen el núcleo de la experiencia de amor que abre el corazón a las demás personas, particularmente a quienes tienen más necesidad ${ }^{5}$. Es el sentido, por lo demás, de la famosa fórmula Ecclesia semper reformanda, difundida en ambientes calvinistas a principios del siglo XVII, con autor desconocido, pero con significado preciso: "recuperar la forma originaria del Evangelio". aportes revelan rasgos fundamentales que hacen de la reforma en curso una renovación evangélica, a partir de las raíces, y no una mera suma de

3 Cf. A. Spadaro, "La reforma della Chiesa secondo Francesco. Le radici ignaziane", en A. Spadaro - C. Galli, La reforma e le riforme, 19-36.

4 Cf. C. M. Galli, "La reforma nissionaria della Chiesa secondo Francesco", en A. SPADARO - C. GaLli, La reforma e le riforme, 37-65.

5 Cf. V. M. Fernández, "Il Vangelo, lo Spirito e la reforma ecclesiale alla luce del pensiero di Francesco", en A. SPADARO - C. GALLI, La reforma e le riforme, 582-589.

6 G. PANI, "Ecclesia semper reformanda: dal XIV al XVI secolo", en A. SPADARO - C. GALLI, La reforma e le riforme, 125-140, 127. No obstante, no debe olvidarse la diferencia acerca de la idea de reforma y el campo particular en que debía realizarse entre Trento y Lutero. Cf. A. MAfFeIS, "Ecclesia semper reformanda: le lezioni della storia e il significato ecuménico”, en A. SPADARO - C. GALLI, La reforma e le riforme, 141-155, 142-143. Cf también H.-C. AsKANI, "Ecclesia semper reformanda", en M. WIRZ (ed.), Riformare insieme la Chiesa (Edizioni Qiqajon, Magnano 2016) 13-38. 
cambios no guiados, ante todo, por criterios teológicos. "La Iglesia está «a disposición» del Espíritu”.

\section{LA SINODALIDAD COMO CATEGORÍA CLAVE}

Es posible apreciar que la categoría de sinodalidad acrecienta su importancia en la eclesiología actual, incluso en la agenda de una reforma. Lo que hoy parece más oportuno y adecuado desde los puntos de vista teológico, pastoral, ecuménico y cultural, incluso desde la perspectiva de las instituciones políticas de nuestra época, es también la experiencia eclesial más antigua, la de los primeros siglos. "Desde el punto de vista histórico, el gobierno tradicional de la Iglesia era el sinodal. Ya en el siglo II se tuvieron al menos cincuenta sínodos en Palestina, en África del norte, en Roma, en la Galia y en otros lugares", recuerda O’Malley ${ }^{8}$. El desajuste que muchas personas experimentan entre características importantes en la forma actual de organización de la Iglesia católica y las que se expresan en las estructuras sociopolíticas conforme a la conciencia humanista de nuestra época, en muy alta medida depende de un factor histórico-cultural muy preciso, ya formulado -entre otros, por un autor no sospechado de progresismo, el cardenal norteamericano Avery Dulles-, pero no asumido en la conciencia eclesial: "Las actuales estructuras de la Iglesia, especialmente en el catolicismo romano, tienen una impronta muy fuerte de las pasadas estructuras sociales de la sociedad europea occidental", esto es, "en la práctica permanece un modo de gobierno heredado de las monarquías europeas del siglo XVIII" ${ }^{\text {. Nadie }}$ puede pretender que resulte una tarea fácil distinguir aquello que representa una forma histórica variable de un valor teológico más permanente, pero debe quedar igualmente claro que, a menudo, se ha revestido de argumentos teológicos -invocando una inmovilidad a determinadas

M. Mellone, "Lo Spirito e il Vangelo: sorgenti permanente dell rinnovamento della Chiesa”, en A. SPADARO - C. GALli, La reforma e le riforme, 571-581, 581.

8 J. O’MAlLEY, "La reforma nella vita della Chiesa", 86.

9 A. Dulles, Models of the Church (Doubleday, New York $\left.{ }^{5} 2002\right) 191$.

10 H. Legrand, "Quelques réflexions ecclésiologiques sur l'Histoire du concile Vatican II', en Revue des sciences philosophiques et théologiques 90 (2006) 495-520, 516. Cf. C. Schickendantz, "Sinodalidad en todos los niveles. Teología, diagnóstico y propuestas para una reforma institucional”, en V. AZCUY - C. CAAmaño - C. M. Galli (eds.), La Eclesiología del Concilio Vaticano II (Agape, Buenos Aires 2015) 513-534. 
prácticas de gobierno y nociones de autoridad-a ideas que tienen claros orígenes en la cambiante historia de las ideas políticas. Precisamente, la conciencia histórica que hoy poseemos es un factor de primer orden que impacta profundamente en la reflexión sobre la reforma de la Iglesia.

Si bien es verdad que, como ha constatado $H$. Legrand, a la vigilia del Vaticano II el tema de la sinodalidad "parecía extraño a la teología católica oficial"11, por varios motivos él ha devenido en tiempo reciente una categoría clave en la eclesiología católica. Tres parecen ser los elementos que determinan su actualidad: la sensibilidad democrática de los pueblos, las investigaciones histórico-teológicas y el contacto con las otras iglesias en el diálogo ecuménico. Es verdad que la palabra refiere -históricamente- a asambleas generales de representantes eclesiales de distinto tipo y ha sido utilizada desde antiguo como sinónimo del término concilio $^{12}$, pero alude también a un elemento o principio que caracteriza constitutivamente a la Iglesia como comunión de creyentes y comunión de iglesias a partir del misterio trinitario fundante de esta communio. En el que representa, quizás, uno de los discursos más importantes de su pontificado referido a la eclesiología, el papa Francisco afirmó en 2015: "el camino de la sinodalidad es el camino que Dios espera de la Iglesia del tercer milenio. Lo que el Señor nos pide, en cierto sentido, ya está todo contenido en la palabra «Sínodo»"13. Propone pensar, con la eclesiología del Vaticano II, una Iglesia sinodal como "una pirámide invertida" en la que se integran el pueblo de Dios, el colegio episcopal y el mismo sucesor de Pedro. Dicha sinodalidad, entendida como "dimensión constitutiva de toda la Iglesia", se realiza a diversos "niveles".

11 H. Legrand, "La sinodalità al Vaticano II e dopo il Vaticano II", en Associazione Teologica Italiana (ed.), Chiesa e Sinodalità. Coscienza, forme, processi (Glossa Edizioni, Milano 2007) 67-108, 75.

12 Cf. H. J. Sieben, "Synode. I. Historisch-theologisch", en Lexikon für Theologie und Kirche. Bd. 9 (Herder, Freiburg i.Br. ${ }^{3} 2009$ ) 1186-1187.

13 "Discurso en la Conmemoración del 50 Aniversario de la institución del Sínodo de los Obispos" (17/10/2015). Cf. http://w2.vatican.va/content/francesco/es/ speeches/2015/october/documents/papa-francesco_20151017_50-anniversariosinodo.html 
Se trata, por tanto, de promover una sinodalidad efectiva en todos los niveles de la vida de la Iglesia (diocesano ${ }^{14}$, regional ${ }^{15}$, universal), involucrar a todas las personas y encontrar su traducción adecuada en todas y cada una de las instituciones. La sinodalidad implica actitudes adecuadas, especiales formas de proceder, determinadas dinámicas relacionales, precisas garantías jurídicas. Si es verdad que la sinodalidad requiere una conversión personal -moral, pastoral y teológica- de los creyentes, también es verdad que "solo una transformación en el plano de la figura colectiva puede sostener adecuadamente un cambio en la autoconciencia"16.

\section{UNA AGENDA COMPLEJA Y ARTICULADA DE REFORMAS}

La reforma incluye una serie de asuntos que están intrínsecamente vinculados. Pero, al mismo tiempo, cada uno de ellos tiene una dinámica específica, debates particulares, conceptos clave precisos, impactos ecuménicos y culturales también distintos. Todos tienen en común un momento eclesial reciente, peculiar y fundante: el Vaticano II. Pero en ningunos de los asuntos el estado de la cuestión es ya el mismo que el de cincuenta años atrás. Hay procesos de recepción bien visibles que, en definitiva, son parte del Concilio mismo y su dinámica connatural.

(a) La doctrina del sensus fidei de todo el pueblo de Dios ha sido recuperada en el capítulo segundo de Lumen gentium; expresa el carácter de sujeto activo de todos los bautizados y bautizadas puesto que participan de la "función profética de Cristo" (LG 12a). No obstante, esta doctrina no ha encontrado todavía en la enseñanza oficial el lugar que le corresponde, aunque se advierten algunos progresos ${ }^{17}$.

14 Cf. G. RouThier, "Il rinnovamento della vita sinodale nelle chiese locali", en A. SPADARO - C. GALLI, La reforma e le riforme, 233-247.

15 Cf. S. Scatena, “Da Medellín ad Aparecida: la 'lezione' di un'esperienza regionale per una ricerca di forme e stili di collegialità effettiva”, en A. SPADARO - C. GALli, La reforma e le riforme, 248-267. Un texto con evaluaciones y sugerencias muy ponderadas a partir de una experiencia regional concreta.

16 S. Noceti, "Riforma e inculturazione della Chiesa in Europa. Un annuncio da ricomprendere, una figura di Chiesa da ripensare, un 'caso serio' da affrontare”, en A. Spadaro - C. Galli, La reforma e le riforme, 504-520, 511.

17 Cf. International Theological Commission, "Sensus fidei in the Life of the Church", 2014, en www.vatican.va/roman_curia/congregations/cfaith/ cti_documents/rc_cti_20140610_sensus-fidei_en.html 
Se trata, ante todo, de reconocer la universitas fidelium como sujeto específico de autoridad en la Iglesia irreductible al magisterio y a la teología, en orden a "pensar y garantizar la circularidad entre sensus fidei y magisterio como criterio para el ejercicio de la sinodalidad" 18 . En la praxis eclesial son necesarios "lugares y formas de escucha y de diálogo", donde se activen procesos de discernimiento en los que los fieles devengan verdaderos actores. La Iglesia católica tiene argumentos diversos y mucho más profundos que las modernas sociedades democráticas para dar la palabra y garantizar jurídicamente su escucha y participación en las deliberaciones y decisiones, puesto que cree en la acción del Espíritu que Dios no niega a todo creyente, más aún, a cada ser humano de buena voluntad "en cuyo corazón obra la gracia de modo invisible" (GS 22). Desgraciadamente este debate teológico ha estado cargado de inmovilismo, por un lado, y de superficialidad, por otro. La traducción jurídica de la idea teológica de LG 12 en el Código de derecho canónico (CIC), por lo demás, es insuficiente ${ }^{19}$.

(b) Si a partir de las enseñanzas conciliares y, más recientemente, de las del papa Francisco se detecta una renovación en la concepción teológico-pastoral de la figura del ministerio episcopal y, por consiguiente, la puesta al día de sus criterios de elección, queda por ver el impacto concreto que esto tendrá en la vida de la Iglesia ${ }^{20}$. Un aspecto particular obtuvo una reflexión destacada en el Seminario sobre la reforma de 2015: la vinculación del obispo con su propia diócesis en el marco de la intrínseca relación entre collegium episcoporum y communio ecclesiarum. Como advertía hace tiempo Y. Congar, se trata de afrontar un asunto - un error- de larga data: junto "al redescubrimiento de la iglesia local", se debe proseguir "el impulso por el que el Vaticano II logró superar la tendencia, tan señalada en la historia de la eclesiología, a aislar las mediaciones, las estructuras de autoridad, desarro-

18 Cf. D. Vitali, "La circolarità tra sensus fidei e magisterio come criterio per l'esercizio della sinodalità nella Chiesa", en A. SPADARO - C. GALli, La reforma e le riforme, 189-206, 202.

19 Cf. M. WijLens, "Riforma e rinnovamento nella normativa canonica: attuare il Concilio Vaticano II", en A. SPADARO - C. GALLI, La reforma e le riforme, 309-329, 328.

20 Cf. D. Fares, "La figura del vescovo in Papa Francesco", en La Civiltà Cattolica 3959 (2016) 433-449. 
llándolas por separado, en sí mismas. Se ha empezado a descubrir de nuevo su inserción como servicios funcionales en las comunidades" ${ }^{21}$.

Precisamente, algunas interpretaciones de las formulaciones de $L u$ men gentium 22 han permitido una cierta disociación doctrinal entre collegium episcoporum y communio ecclesiarum que ha dominado en buena medida la recepción hecha por parte de la enseñanza posterior $^{22}$. En particular, a partir de la debatida afirmación del documento Communionis notio de 1992, según la cual la Iglesia universal "es una realidad ontológica y temporalmente previa a cada concreta Iglesia particular" $\left(n^{\circ} 9\right)$, se podía pensar en la dimensión colegial del obispo como un dato independiente de su relación con la iglesia local. En efecto, el motu proprio Apostolos suos (1998), sobre las conferencias episcopales, hace referencia a dicho texto para deducir que la participación del obispo -singularmente considerado- en el colegio episcopal es algo que precede a su tarea en una iglesia particular. En esta perspectiva, un obispo no constituiría una realidad interna a la iglesia local, sino que pertenecería a un organismo que la gobierna desde fuera. La comunión de los obispos en el colegio episcopal se presenta, de esta manera, como una realidad independiente de la comunión de las iglesias locales. Aquí se fundamenta teóricamente una práctica habitual que debería disminuir: la ordenación "absoluta" de obispos "titulares", sin atribución de una iglesia local real"23. "Si se tiene en cuenta el número actual de estos obispos ad titulum, no se puede más que llamar a una corrección progresiva de esta grave distorsión teológica de la práctica eclesial, que disocia ordenación sacramental y presidencia de una Iglesia local"24.

21 "Estructuras esenciales para la Iglesia del futuro", Concilium 60 extra (1970) 304314, 306 (cursiva mía).

22 Esta temática está particularmente desarrollada en el aporte de H. LEgrand, "Communio ecclesiae, communio ecclesiarum, collegium episcoporum", en A. SPADARO - C. GALLI, La reforma e le riforme, 159-188.

23 Cf. S. Dianich, Diritto e teologia. Ecclesiologia e canonistica per una riforma della Chiesa (Dehoniane, Bologna 2015) 178-179.

24 J. Famerée, "Scambio di doni: Chiesa cattolica e Chiese orientali", en A. Spadaro - C. Galli, La reforma e le riforme nella Chiesa, 408-421, 418. Cf. S. Dianich, "Primato e collegialità episcopale: problema e prospettive", en A. SPADARO - C. GALLI, La reforma e le riforme, 271-292, 275. Según el Anuario pontificio de 2016, sobre 5088 obispos, 2472, casi la mitad, son titulares (1080 incluidos los auxiliares) o eméritos (1392). 
Es necesario otorgar más vigor al estatuto de las diócesis y a la radicación de los obispos al interior del Pueblo de Dios. En esta línea se ubican sugerencias formuladas por varios autores: revitalizar los consejos y los sínodos diocesanos; revisar el procedimiento de selección y nombramiento de obispos; ordenar a los nuevos obispos en sus propias catedrales, en medio de su pueblo; enriquecer simbólicamente el rito de acogida al nuevo obispo si ya ha sido ordenado; disminuir sensiblemente las ordenaciones de obispos para cargos protocolares o administrativos; etc. ${ }^{25}$.

(c) Un punto en deuda ya desde hace muchas décadas reside en las formas de elección de nuevos obispos en el ordenamiento latino-occidental, que rige iglesias de África, Asia, América del Norte, Europa, América Latina y Oceanía. ¡Nada menos! Probablemente, la actual forma de elección y designación será estudiada por los historiadores del futuro como un ejemplo visible de hasta dónde llegó el proceso milenario de concentración progresiva de la Iglesia en la figura papal. El procedimiento concreto a privilegiar hacia el futuro debería basarse ante todo en razones teológicas. Un proceso que incluya una participación más amplia y el discernimiento de la comunidad local a través de la consulta a diversos miembros, una mayor intervención y el reconocimiento de los obispos de las iglesias vecinas o regionales y, finalmente, la del obispo de Roma, expresa mejor una teología de la Iglesia como comunión sinodal y colegial en sus distintos niveles. Aunque no es una tarea sencilla, es necesario encontrar formas prácticas más equilibradas que las actuales conforme a los tres niveles de ejercicio de la sinodalidad (local, regional, universal).

La diversidad de procedimientos utilizados en la historia de la Iglesia deja un amplio campo abierto a la creatividad; en ningún período histórico ha existido una única manera para la selección de obispos. Las formas históricas progresivas de clericalización o de exclusión de los laicos, particularmente desde el inicio del segundo milenio, tuvieron que ver, en buena medida, con la búsqueda de una mayor libertad $\mathrm{e}$ independencia de la Iglesia frente a los poderes estatales y como un servicio a las iglesias locales. No obstante, el déficit pneumatológico, el oscurecimiento de la dimensión sinodal y la concentración de la Iglesia en el primado romano condicionaron progresivamente de una manera

25 Cf. H. Legrand, “Communio ecclesiae”, 186-187. 
negativa también la participación de los obispos diocesanos y de las iglesias locales en el proceso de discernimiento y elección ${ }^{26}$.

Todavía hay diócesis antiguas que mantienen sus propios procedimientos de elección con algunas consultas obligatorias en comunión con el obispo de Roma. Podrían preverse otras propuestas de descentralización: estimular una diversidad de prácticas y metodologías que presten más atención a las particularidades y costumbres de las distintas iglesias regionales y locales. Esta sugerencia -y otras que podrían añadirse ${ }^{27}$ se fundamentan en una idea teológica central: la revalorización de las iglesias diocesanas y la relación fundamental del obispo con su comunidad eclesial local. Representa, además, un punto neurálgico en una "saludable descentralización" (EG 16).

(d) Después del Concilio ha existido una limitada reformulación del ministerio presbiteral. Este desarrollo tendría una explicación, al menos en parte, en lo sucedido en el mismo Vaticano II. Allí a diferencia del tratamiento del tema del episcopado e, incluso, del sacerdocio común de los fieles, el tema del clero no ocupó un lugar relevante. Esta es una constatación de numerosos autores. A. Riccardi afirma que en este punto se visibiliza la carencia de una seria reforma de la Iglesia del siglo XX. De modo diverso a lo sucedido con Trento, opina el historiador italiano, no poseemos realmente un sacerdote del Vaticano II como un modelo, sino una actualización del modelo clásico ${ }^{28}$.

26 Cf. J. Gaudemet, "La participation de la communauté au choix de ses pasteurs dans I'Eglise latine”, en Ius Canonicum 14 (1974) 308-326; R. Potz, "Bischofsernennungen. Stationen, die zum heutigen Zustand geführt haben", en G. Greshake (ed.), Zur Frage der Bischofsernennungen in der römisch-katholischen Kirche (Herder, Freiburg i.Br. 1991) 17-50; J. Huels - R. Gaillardetz, "The Selection of Bishops: Recovering the Traditions", en The Jurist 59 (1999) 348-376.

27 En particular, el canon 377,3 posee una formulación restrictiva. Una nueva normativa, más adecuada, podría estipular con fuerza vinculante el proceso de consulta y, además, posibilitar otras formas e, incluso, prescribir procedimientos que incluyan espacios comunitarios de discernimiento más inclusivos y sensibles a las necesidades de las diócesis. Por lo demás, la situación devaluada del consejo presbiteral y el consejo pastoral diocesano en el derecho es manifiesta. Aunque está normado el posible carácter deliberativo del consejo presbiteral ( $\mathrm{cn} .500)$, no hay ningún caso previsto; la existencia del consejo pastoral ni siquiera es obligatoria (cn. 511). El derecho canónico debería garantizar procedimientos sinodales a todos los niveles.

28 Cf. A. Riccardi, "Lezioni dalle reforme del XX secolo", en A. Spadaro - C. GALLI, La reforma e le riforme, 108-124, 123. Sin negar la afirmación de Riccardi 
De este modo, argumenta, bajo tantas presiones y nuevos requisitos, existen amplios sectores del clero bajo estrés, en crisis, sujetos a múltiples y diversas demandas y, a menudo, en número cada vez menor en extensas regiones de la geografía eclesial. Se comprende, entonces, la existencia de sectores del clero con horizontes reducidos, frecuentemente orientados por modelos eclesiológicos de un catolicismo minoritario, identitario, incapaz de insertarse en la complejidad existente en la vida de la Iglesia y del mundo actual ${ }^{22}$. A su juicio, en síntesis, el problema del clero sigue siendo un punto importante para la realidad básica y cotidiana del catolicismo, por su liderazgo como clase dirigente, también para afrontar serena y efectivamente el tema del laicado, de las mujeres en particular, en la Iglesia. Riccardi advierte una primera señal de dificultad en la falta de recepción del mensaje de Francisco en "consistentes sectores del clero" ${ }^{30}$. A partir de este diagnóstico, también, que de ningún modo pretende ser exhaustivo ni reflejar la complejidad en realidades tan diversas, parece claro que la reforma del ministerio no puede provenir de pequeñas adaptaciones a la luz de lo vivido y enseñado particularmente en los últimos siglos, sino, operando como lo hizo el Concilio, a la luz crí-

y de otros autores, no debe subestimarse el significado que tiene, por ejemplo, la reformulación del ministerio presbiteral como orientado, ante todo, al anuncio de la palabra, "lo primero" (PO 4). Cf. A. MAfFeIs, "Ecclesia semper reformanda", 143-144.

29 Algunos diagnósticos breves hechos por FRANCISCO parecen confirmar esta lectura. Un ejemplo puede verse en el diálogo con los jesuitas de octubre de 2016 publicado en La Civiltà Cattolica 3995 (2016) 417-431: "El discernimiento, la capacidad de discernir, es el elemento clave. Y estoy notando justamente la carencia del discernimiento en la formación de los sacerdotes. En efecto, corremos el riesgo de habituarnos al 'blanco o negro' y a lo que es legal. En principio, estamos bastante cerrados al discernimiento. Una cosa es clara: hoy, en una cierta cantidad de seminarios ha vuelto a instaurarse una rigidez que no es cercana a un discernimiento de las situaciones. Es algo peligroso, porque puede conducir a una concepción de la moral que tiene un sentido casuístico." Cf. también su discurso a la comunidad del seminario regional pugliese, 'Pío XI', de diciembre de 2016, http://press.vatican. $\mathrm{va} /$ content/salastampa/it/bollettino/pubblico/2016/12/10/0892/01990.html; o sus exhortaciones a los seminaristas de la diócesis de Roma el día anterior, el 9 de diciembre, http://w2.vatican.va/content/francesco/it/cotidie/2016/documents/ papa-francesco-cotidie_20161209_preti-autentici.html

30 A. RicCardi, "Lezioni dalle reforme del XX secolo", 123. Cf. A. Spadaro, "La reforma della Chiesa secondo Francesco", 31-33. Referido a una figura nueva de parroquia, cf. S. NOCETI, "Riforma e inculturazione", 512-514. 
tica y creativa de la gran tradición que se remonta a los orígenes. Una tarea pendiente análoga puede apreciarse al tomar nota de los debates referidos al sacramento del matrimonio con ocasión de los recientes sínodos de los obispos y de la exhortación Amoris laetitia. Parece que una tarea de esta envergadura no se está llevando a cabo de una manera sistemática en la Iglesia de hoy.

(e) Si bien es verdad que el tema del laicado tuvo un desarrollo destacable en el Vaticano II -ninguna instancia eclesial anterior posee esa envergadura en la calidad de su tratamiento, tampoco un documento conciliar exclusivo sobre la temática, Apostolicam actuositatem-, los pasos posteriores han sido lentos y, a menudo, contradictorios. La exhortación apostólica Christifideles laici de 1988 afirmaba con claridad: "En realidad, el desafío que los Padres sinodales han afrontado ha sido el de individuar las vías concretas para lograr que la espléndida "teoría» sobre el laicado expresada por el Concilio llegue a ser una auténtica "praxis» eclesial." (ChL 2). Este es uno de nuestros mayores desafíos actuales: traducir en la práctica eclesial, a todos los niveles, la teología del laicado que como Iglesia poseemos, incluida su corresponsabilidad en el discernimiento y su cooperación en el gobierno de las comunidades eclesiales. En caso contrario, las múltiples enseñanzas magisteriales, que constituyen verdaderos textos programáticos, permanecen como una "imagen ideal" o una mera "retórica teológica" ${ }^{31}$. No hay reforma de la Iglesia creíble sin pasos concretos y visibles en esta dirección. Esta temática es, también, uno de los ejemplos claros de las limitaciones que han existido para traducir en normas jurídicas las ideas teológicas conciliares.

Entre los múltiples ejemplos concretos que podrían destacarse, formulo uno importante cargado de consecuencias. Después de un largo proceso de consultas y debates en el proceso de su revisión, el CIC de 1983 afirmó, deliberadamente, que "en el ejercicio de dicha potestad (de régimen o jurisdicción), los fieles laicos pueden cooperar a tenor del derecho" (cn 129, 2). De hecho, el CIC prevé ya varios casos: jueces, defensores del vínculo, auditores, abogados, jefes de finanzas en diócesis y parroquias, superiores y miembros de consejo de instituciones laicas

31 S. Demel, Zur Verantwortung berufen. Nagelproben des Laienapostolats (Herder, Freiburg i.Br. 2009) 41, 57. Cf. también S. DiANICH, La chiesa cattolica verso la sua reforma (Queriniana, Brescia 2014) 107-121. 
de vida consagrada o sociedades de vida apostólica ${ }^{32}$. Por tanto, es claro que la Iglesia tiene la autoridad para admitir a laicos y laicas a ciertos cargos y funciones que implican el ejercicio del poder de gobierno, esto es, el poder público necesario para realizar válidamente un acto jurídico (legislativo, ejecutivo o judicial) con una decisión vinculante para la vida eclesial. Las diversas experiencias históricas y la misma legislación canónica sugieren que "es evidente que, en la discusión acerca de quiénes pueden ejercer el poder del gobierno, no estamos en el ámbito de la ley divina inmutable, sino en la ley meramente eclesiástica que puede cambiar, ha cambiado, y es muy probable que todavía puedan verse ulteriores desarrollos" ${ }^{33}$. Con prudencia, pero también con creatividad, deben explorarse nuevos caminos en esta forma de cooperación en la sacra potestas ${ }^{34}$.

(f) El reconocimiento justo y adecuado de las mujeres en la vida de la Iglesia es, en buena medida, una agenda pendiente. En particular, la escasa o devaluada presencia de mujeres en organismos eclesiales es uno de los desajustes institucionales más visibles, que obedece, sobre todo, a una cultura institucional clerical. Una práctica institucional más inclusiva, más allá de las razones específicamente evangélicas y

32 Cf. J. Beal, "The Exercise of the Power of Governance by Lay People: State of the Question", en The Jurist 55 (1995) 1-92, 52-88; L. Orsy, "Lay Persons in Church Governance? A Disputed Question", en America 174, 11 (1996) 10-13; J. Coriden, "Lay Persons and the Power of Governance", en The Jurist 59 (1999) 335-347.

33 J. Huels, "The Power of Governance and its Exercise by Lay Persons. A Juridical Approach", en Studia canonica 35 (2001) 59-96, 72. Era también la interpretación de la mayoría de los canonistas incluso con la restrictiva norma del Código de 1917.

34 El Concilio usa la expresión "jurisdicción" solo 9 veces; prefiere potestas o sacra potestas, términos que según el contexto denotan el poder de orden o de jurisdicción o ambos en el mismo sujeto. La doctrina conciliar sobre el asunto es muy escueta, incluso no especifica la relación entre el esquema de las tria munera-santificar, enseñar y gobernar- y la sacra potestas, ni establece una correlación clara entre ella y la doctrina tradicional que distingue entre poder de orden y de jurisdicción, de la cual el Concilio toma distancia con una visión más unitaria de la potestad sacramental. El Vaticano II no ha afirmado explícitamente la participación de fieles laicos en el ejercicio de la sacra potestas, tampoco lo ha negado. La comprensión de la cuestión de la potestas en la Iglesia merecería un serio estudio a la luz de la pneumatología, la eclesiología, la historia y el derecho canónico. Cf. J. BEAL, “The Exercise of the Power of Governance", 10, 15-17. 
eclesiales, es hoy una exigencia de justicia acorde con los signos de los tiempos. Varios pasos más en una dirección correcta podrían ser dados incluso con la teología "oficial" sobre lo femenino hoy existente. $\mathrm{Al}$ respecto, destaco un punto particular. En múltiples ocasiones se utiliza en ámbitos de gobierno eclesial el argumento proveniente de la teología de H. U. von Balthasar acerca del principio petrino y del principio mariano para responder al lugar de las mujeres en la vida de la Iglesia. Sin desconocer los aportes teológicos que ofrece esta perspectiva, parece oportuna una mayor conciencia de los límites que encierra la concepción de lo femenino en dicho pensamiento ${ }^{35}$.

Es necesario llevar adelante una agenda progresiva, decidida e imaginativa. La contribución de varones y mujeres es un requisito necesario para mejorar las condiciones que favorezcan los procesos de discernimiento y gobierno. Una sana heterogeneidad beneficia tomar decisiones más innovadoras. Propuestas razonables y practicables no faltan.

Entre las sugerencias que pueden aportarse se cuenta la solicitud de una investigación teológica sobre la posible ordenación diaconal de mujeres. El papa Francisco ha instituido una comisión internacional que colaborará a un discernimiento oportuno. Algunas breves consideraciones pueden incluirse aquí. A partir del importante texto de la Comisión Teológica Internacional de 2002 sobre el tema del diaconado, "El diaconado: evolución y perspectivas" ${ }^{36}$, parece oportuno abrir un diálogo sereno y sistemático acerca de una posible ordenación de mujeres para el diaconado. La historia muestra que, en el pasado, la Iglesia ha tenido la posibilidad y, más aún ha percibido el deber de remodelar las figuras ministeriales ordenadas atendiendo, por una parte, a la tradición rica y variada que se remonta a los orígenes de las primeras comunidades cristianas y, por otra, a las necesidades de la época. Una objeción repetida debe ser esclarecida: no representa un asunto de poder o de mera afirmación de la dignidad de las mujeres, sino ante todo del reconocimiento del valor teológico de la gracia sacramental para la Iglesia en el ejercicio de ministerios que ya se realizan en las diversas comunidades

35 Cf. C. Schickendantz, "Una 'forma de pensamiento' central en la obra de Hans Urs von Balthasar. La reflexión sistemática sobre la mujer y lo femenino”, en Teología 94 (2007) 523-549.

36 Cf. http://www.vatican.va/roman_curia/congregations/cfaith/cti_documents/ rc_cti_index-doc-pubbl_it.html 
cristianas. Por lo demás, una eventual práctica futura en este sentido podría realizarse en el modo como fue propuesto el diaconado permanente en los debates conciliares: abrir la posibilidad de estas ordenaciones en regiones específicas de la Iglesia católica que, después de un proceso de discernimiento, encuentren en ellas un punto de enriquecimiento en el servicio al pueblo de Dios.

(g) La reflexión teológica y jurídica sobre las conferencias episcopales y la ampliación de sus campos de competencia arribó a un visible estancamiento en las décadas recientes, que puede verificarse incluso en el interés y el número, ambos escasos, de publicaciones en la bibliografía teológica especializada. El mismo Francisco calificó el estado de la cuestión con palabras muy elocuentes en un texto papal: "este deseo no se realizó plenamente" (EG 32). Los argumentos teológicos del estancamiento están bien individualizados. En particular, creo que la opinión de Francis Sullivan acerca de que "es la perspectiva de Ratzinger la que ha prevalecido" en las últimas décadas es correcta ${ }^{37}$. No obstante, pienso que debe advertirse un matiz: en los textos del Sínodo de 1985 y en el documento Apostolos suos no se materializaron completa y explícitamente sus posiciones más extremas. Califico de extremas aquí a estas ideas: (1) las conferencias no tienen "base teológica"; (2) la autoridad de la conferencia resulta (solo) de la suma de la autoridad de los individuos; (3) no se les aplica la noción de colegialidad sino, a lo más, en sentido "impropio"; (4) no tienen mandatum docendi; (5) queda excluida, por lo tanto, toda analogía entre las conferencias episcopales con las experiencias sinodales y conciliares regionales de la antigüedad. De allí que, en la posición del entonces cardenal Ratzinger, de ningún modo se puede hablar de una "instancia intermedia" -como sí lo hace ahora también el papa Francisco- ${ }^{38}$, de una "forma estructural triádica" o de una "estructura eclesial tri-

37 "The Teaching Authority of Episcopal Conferences", en Theological Studies 63 (2002) 472-493, 491.

38 Cf. http://w2.vatican.va/content/francesco/it/speeches/2015/october/documents/ papa-francesco_20151017_50-anniversario-sinodo.html; G. GRESHAKE, “'Zwischeninstanzen' zwischen Papst und Ortbischöfen”, en H. Müller - H. PotTMEyer (eds.), Die Bischofskonferenz. Theologischer und juridischer Status (Patmos, Düsseldorf 1989) 88-115; L. SAnTEdi Kinkupu, "Inculturazione del Vangelo e reforma della Chiesa in Africa", A. Spadaro - C. Galli, La reforma e le riforme, 534-551, 546. 
membre", como refieren varios autores. Los caminos de renovación en este punto son complejos desde las perspectivas teológica, jurídica y pastoral ${ }^{39}$.

(h) El sinodo de los obispos, creado durante la sesión final del Concilio, también requiere mejoras cualitativas. Existe una reflexión en curso conducida por la misma secretaría general de este "instituto eclesiástico central" con un resultado todavía por desarrollar y exponer ${ }^{40}$. En su estado actual existen "nudos irresueltos" necesitados de reforma ${ }^{41}$. Las conferencias episcopales tienen una limitada capacidad para intervenir en la fase preparatoria, tampoco es relevante la capacidad de decisión de la asamblea acerca de su composición, ni de su orden del día, ni de su periodicidad o sus resultados; nunca tuvo poder deliberativo; su representatividad en relación a la colegialidad es problemática, etc. ${ }^{42}$. Si bien no debe minusvalorarse el servicio que ha prestado, sigue siendo una institución teológicamente insatisfactoria y ecuménicamente poco atractiva. Algunas de sus principales limitaciones son claras desde su mismo origen: más que una expresión de la colegialidad, como lo esperaba la mayoría en el Concilio, el sínodo nació como "ayuda para el ministerio del primado", observaba Joseph Ratzinger en 1965. Christus Dominus desarrolla la idea del sínodo de los obispos "esencialmente "desde abajo", desde la idea del ministerio episcopal y de la responsabilidad por la Iglesia universal que compete a los obispos en cuanto tales. Por el contrario, el motu proprio papal construye el sínodo totalmente "desde arriba», desde el primado papal”43. El documento no alude a la colegialidad, no cita la constitución Lumen gentium aprobada meses antes, ni refiere a la relación

39 Un estado de la cuestión, en particular, los argumentos en juego en estas décadas y algunas recomendaciones más prácticas, pueden verse en C. SCHICKENDANTZ, "Le conferenze episcopali. 'Questo auspicio no si è pienamente realizzato' (EG 32)”, en A. Spadaro - C. Galli, La reforma e le riforme, 347-366.

40 Cf. L. Baldisseri (ed.), A cinquant'anni dall'Apostolica solicitudo. Il Sinodo del vescovi al servicio di una Chiesa sinodale (Libreria Editrice Vaticana, Città del Vaticano 2016).

41 Cf. A. Indelicato, Il sinodo dei vescovi. La collegialità sospesa 1965-1985 (Il Mulino, Bologna 2008) 352ss.

42 Cf. P. GHerri, "L'evoluzione della normativa canonica sul Sinodo dei vescovi", en L. BALDisseri, A cinquant'anni, 227-261.

43 J. Ratzinger, Obras completas VII/1. Sobre la enseñanza del Concilio Vaticano II (BAC, Madrid 2013) 478-479. 
entre pastores y todo el pueblo de Dios (sensus fidei). La observación de J. O’Malley es relevante: "Probablemente sin darse cuenta, Pablo VI redefinió radicalmente lo que la palabra sínodo había significado desde los inicios de la Iglesia. Los sínodos eran órganos decisorios. Con esa redefinición la única reforma más importante del Concilio Vaticano II con respecto al ordenamiento eclesial en buena medida se debilitaba" ${ }^{\prime 4}$. Aunque, reconoce allí el autor, se había puesto una semilla destinada a madurar en el futuro.

Este es otro caso más, muy visible, de la insuficiente articulación entre primado (uno), colegialidad (algunos) y sinodalidad (todos) en la Iglesia actual. Una sinodalidad bien vivida a todos los niveles es condición de un ejercicio colegial y primacial adecuados; solo en esa dinámica de escucha y participación se hace un discernimiento episcopal como corresponde. Exige una "circularidad virtuosa" en lugar de la reductio ad unum centralizadora en la Curia romana del posconcilio ${ }^{45}$. El procedimiento en los sínodos de 2014 y 2015, articulando experiencias de sinodalidad y colegialidad, se mueve en una dirección correcta.

(i) Conversión del papado. En 1995 Juan Pablo II concretó un paso significativo. En la encíclica Ut unum sint invitó a los obispos y teólogos/as de las diversas iglesias cristianas a entablar un diálogo sobre el modo que debía adquirir el ministerio petrino en la situación actual; una invitación a "encontrar una forma de ejercicio del Primado que, sin renunciar de ningún modo a lo esencial de su misión, se abra a una situación nueva” (UUS 95). La única encíclica ecuménica del posconcilio no solo invitaba al diálogo, sino que también ofrecía indicaciones para esa posible nueva "forma de ejercicio". La caracterización, ante todo, como obispo de Roma -que en el posconcilio ha tenido un desarrollo importante-, su explícita subordinación a la Palabra de Dios -reclamada por la teología de la Reforma-, la distinción entre "esencia" y "ejercicio" con perspectiva histórica, la valoración de los otros interlocutores y la búsqueda de un reconocimiento como supuesto de un ejercicio efectivo del primado, la repetida inserción de su ministerio en el colegio de los obispos son todos aspectos que po-

44 "La reforma nella vita della Chiesa", 100.

45 Cf. D. Vitali, "I soggetti della sinodalità alla luce dell'ecclesiologia del Concilio Vaticano II", en L. Baldisseri, A cinquant'anni, 141-189, 182ss.; D. Vitali, Verso la sinodalità (Edizioni Qiqajon, Magnano 2014) 100-106. 
seen un enorme relieve. Por tanto, la misma invitación ofrecía perspectivas y áreas temáticas a considerar ${ }^{46}$. En Evangelii gaudium Francisco renovó esta iniciativa con una expresión muy significativa: "una conversión del papado". Formuló también una evaluación autocrítica de lo acontecido luego de la propuesta de 1995: "Hemos avanzado poco en ese sentido" (EG 32).

Dado el lugar singular que tiene el obispo de Roma en la vida de la Iglesia buena parte de la agenda de reforma eclesial implica de una u otra forma su figura, la "forma de ejercicio" con repercusiones amplias, incluso en el campo ecuménico, sin olvidar -con realismo- que "solo un Papa puede cambiar el papado" ${ }^{47}$.

Una reforma fundamental, condición de todas las demás, fue enunciada hace 50 años también por Yves Congar. Hay que superar, escribía, "el régimen concreto de la Iglesia, actualmente dominado por cierto ejercicio de la primacía papal, o sea el que comporta el actual sistema de la Curia y la centralización romana" ${ }^{38}$. Este tipo de gobierno cotidiano de toda la Iglesia por el Papa, en cada asunto, fue deducido por los canonistas a partir de los poderes que le atribuye el Vaticano I. No hay duda que, en el plano dogmático, el Papa ciertamente posee todas las facultades necesarias para el gobierno cotidiano de toda la Iglesia, pero el Vaticano I no ha definido que un gobierno con estas características correspondiera a Pedro y a sus sucesores. Pretendía establecer que el Papa podría intervenir en todos los casos de necesidad, como "regulación de última instancia". De lo contrario, las definiciones del Vaticano I irían en contra de la "jerarquía de las verdades de la fe" doctrinal muy preciso y delicado -el ejercicio "habitual y cotidiano" de

46 La contribución de S. PIÉ-NINOT, "Verso un ordo communonis primatus como primato diaconale", en A. SpADARO - C. GALLI, La reforma e le riforme, 293-308, 295-301, ofrece nueve puntos precisos en los cuales el Vaticano II desarrolla ulteriormente la enseñanza anterior.

47 P. RicCA, "La Papauté en discussion. Attentes et perspectives pour le III millénaire", en Irénikon 70 (1997) 30-40, 31.

48 Diario del Concilio. Tercera sesión (Editorial Estela, Barcelona 1965) 32.

49 Cf. H. Pottmeyer, "The Petrine Ministry. Vatican I in the Light of Vatican II", en Centro Pro Unione 65 (2004) 20-24, 21: "Es la prevalente interpretación apologética-maximalista, extendida largo tiempo, la que determina hasta hoy la imagen del dogma dentro y fuera de la Iglesia católica." S. PIÉ-NinOT, aporta entre otras ideas, el testimonio de G. Philips, redactor principal de Lumen gentium. Cf. "Verso un ordo communonis primatus", 298. 
gobierno, el "ejercicio extraordinario y último", las causas maiores- en el cual se decide, en buena medida, el grado de reforma y descentralización. La atención a los debates y a las diversas experiencias en la historia de la Iglesia es clave aquí, como en toda la agenda de reformas.

Este paso es también necesario desde el punto de vista ecuménico. La conversión del papado tiene aquí un punto preciso de consideración. Sin ella no hay esperanza de progresos ecuménicos medulares. En particular, la interpretación del Vaticano I es un obstáculo con el cual tropiezan los interlocutores cristianos. En el texto "Le ministère pétrinien", publicado por el Pontificio Consejo para la Unidad de los Cristianos con el fin de colaborar a la evaluación del debate ecuménico suscitado por Ut unum sint, se afirmaba con claridad:

"Prácticamente todos los estudios ecuménicos referidos al primado papal abogan a favor de una relectura, de una reinterpretación o de una re-recepción de las dos definiciones del Concilio Vaticano I a la luz de la única y entera tradición de la Iglesia, que engloba las definiciones de los primeros concilios ecuménicos, la eclesiología de comunión del primer milenio, las mejores experiencias del segundo milenio y algunas ideas fundamentales del Concilio Vaticano II (subsistit in, colegialidad, iglesias locales, comunión real pero incompleta)" ${ }^{" 50}$.

El importante documento de Ravenna de 2007, "Consecuencias eclesiológicas y canónicas de la naturaleza sacramental de la Iglesia. Comunión eclesial, conciliaridad y autoridad", tiene un "significado estratégico". Es el primer documento común de católicos y ortodoxos que afronta la cuestión de la articulación entre sinodalidad y primado, pero es verdad que recién deja abierta la puerta para iniciar el estudio, precisamente, de las prerrogativas del obispo de Roma en el nivel universal y sus formas de ejercicio ${ }^{51}$.

Una observación de W. Henn es iluminadora:

"La reforma más importante en el largo plazo para el progreso ecuménico es continuar con el nuevo estilo de ejercicio del ministerio del primado iniciado por Francisco, y proseguir con cuidado sus esfuerzos por la descentralización, por ejemplo, dando más voz a las

50 "Le ministère pétrinien”, CPPUC Service d'information 109 (2002) 33-47, 45.

51 Cf. P. Coda, "Scambio di doni: Chiesa cattolica e Chiese orientali. Il significato strategico del Documento di Ravenna”, en A. SPADARO - C. GALLI, La reforma e le riforme, 393-407, 400. 
iglesias particulares y las conferencias episcopales y reformando la curia romana" 52 .

Esta idea emergió constantemente en el Seminario de 2015: si los grandes debates - por ejemplo, la reinterpretación de los dogmas del Vaticano I- necesitan procesos extendidos en el tiempo, una serie de pasos, por la vía de los hechos - con gestos y palabras-, colaboran a crear un nuevo escenario. Vivir más plenamente a todos los niveles de la vida eclesial la comunión ya existente, real, aunque parcial, entre las iglesias que reconocen recíprocamente el bautismo, parece una recomendación adecuada que reclama creatividad. La conmemoración común de la Reforma en el año 2017 es una ocasión providencial en este camino ${ }^{53}$.

(j) Curia semper reformanda. La Curia romana en su estado actual es el futo de un largo proceso histórico de desarrollo ${ }^{54}$. Su reforma "ha sido durante siglos un problema recurrente". A juicio de O’Malley y otros autores, la renovación de la Curia, con las numerosas reformas emprendidas a partir de 1588, es un buen ejemplo de una "reforma interna" de un organismo sin que "sea modificado de manera significativa". Por diversos motivos, tampoco el Vaticano II pudo hacerlo; "cuasi una repetición de lo sucedido en Trento" 55 . En tiempo reciente, en parte debido a una sensación generalizada de crisis al final del pontificado de Benedicto y gracias también a iniciativas de Francisco, la reforma de dicho organismo ha obtenido una renovada atención. Su importancia reside tanto desde el punto de vista efectivo,

52 W. Henn, "Scambio di doni: la ricezione dei frutti del dialogo e la reforma della Chiesa”, en A. SPADARO - C. GALLI, La reforma e le riforme, 369-392, 390 (cursiva mía). Henn anota allí múltiples "consejos prácticos", entre ellos, el de favorecer la recepción del texto de convergencia del Consejo Mundial de Iglesias, "La Iglesia: Hacia una visión común" (2013). Un "logro ecuménico extraordinario", que contiene lo que podría llamarse una "jerarquía de las verdades eclesiológicas."

53 Cf. P. De Mey, "Imparare da mezzo secolo di dialogo con le chiese nate dalla Riforma”, en A. SPADARO - C. GALli, La reforma e le riforme, 422-437, 429, 435. Desafíos específicos presentan las llamadas "Iglesias libres" o "pentecostales", cf. J. Scampini, "Pentecostali e cattolici: verso uno scambio di doni per un annuncio rinnovato del Vangelo", en A. SPADARO - C. GALLI, La reforma e le riforme, 438-455.

54 Cf. N. TANnER, "La reforma de la Curia romana a través de la historia", en Concilium 353 (2013) 17-28; H. Hallermann, "Römische Kurie. Dienst und Macht", en I. Riedel-SPANGenberger (ed), Leitungsstrukturen der katholischen Kirche (Herder, Freiburg i.Br. 2002) 101-144.

55 J. O’Malley, "La reforma nella vita della Chiesa”, 106, 87, 101 respectivamente. 
de gobierno, como simbólico. Sus estructuras constituyen la "huella institucional del ministerio petrino del obispo de Roma y condicionan, no solo la comprensión y credibilidad de dicho ministerio, sino también la comprensión y credibilidad de la entera comunidad de los creyentes, la Iglesia" ${ }^{56}$. Ella necesita, sobre todo, una reforma con criterios teológicos, de forma mentis eclesiológica ${ }^{57}$, y no solo una serie de cambios meramente administrativos, abocados a su organización interna más efectiva. Son posibles múltiples pequeños pasos en una dirección correcta; propuestas no faltan, algunas ya están en ejecución, como lo refleja el llamativo discurso de Francisco de diciembre de $2016^{58}$.

Entre otros posibles, un aspecto relevante para todos los espacios de la vida eclesial puede explicitarse aquí: "una Iglesia pobre en su ser y en el aparecer" 59 . Con la expresión "¡cómo quisiera una Iglesia pobre y para los pobres!” al inicio de su pontificado el papa Francisco se situó en la tradición que se remonta a Juan XXIII en su famoso mensaje de setiembre de 1962, un mes antes del comienzo del Vaticano II, y a las iniciativas que en el mismo Concilio deseaban materializar una Iglesia más sencilla y pobre ${ }^{60}$. A la luz de esta tradición un aspecto muy visible de la Curia romana en una época marcada por la inmediatez y cercanía

56 P. Hünermann, El Vaticano II como software de la Iglesia actual (Ed. Universidad Alberto Hurtado, Santiago 2014) 318.

57 Los discursos de Francisco a la curia romana, por su agudeza y radicalidad en las patologías que advierte, encuentran pocas analogías en la historia reciente. Cf. http://w2.vatican.va/content/francesco/es/speeches/2014/december/documents/ papa-francesco_20141222_curia-romana.html; http://w2.vatican.va/content/ francesco/es/speeches/2015/december/documents/papa-francesco_20151221_ curia-romana.html

Cf. http://w2.vatican.va/content/francesco/es/speeches/2016/december/ documents/papa-francesco_20161222_curia-romana.html; M. Semeraro, "La riforma di papa Francesco", en Il Regno Attualità 14 (2016) 433-441.

59 J.C. SCANNONE, "Incarnazione, kenosis, inculturazione e povertà", en A. SpaDaro - C. Galli, La reforma e le riforme, 459-484, 467. Es importante incluir esta perspectiva decisiva que, frecuentemente, no aparece en las propuestas de reformas estructurales de la Iglesia. Además, su vinculación con la temática de la inculturación es significativa. Cf. D. FARES, "'Si è fatto povero per arrichirci con la sua povertà' (2 Co 8,9)", en A. Spadaro - C. Galli, La reforma e le riforme, 485-503.

60 Cf. Francisco, http://w2.vatican.va/content/francesco/es/speeches/2013/ march/documents/papa-francesco_20130316_rappresentanti-media.html; J.C. SCANNONE, "Incarnazione, kenosis", 470ss. 
que ofrecen los medios de comunicación social necesita una revisión decidida: el tipo de vestimentas, el estilo de vida, las formas de tratamiento, en síntesis, la misma cultura institucional. A menudo parecen expresiones de una corte perteneciente a una monarquía europea. Es necesario dar nuevos pasos en la búsqueda de lo que, análogamente considerado, Sacrosanctum concilium proponía como criterio al solicitar la reforma de los ritos litúrgicos: una "noble sencillez" (SC 34).

(k) La constitución del Consejo de cardenales, "institución que el papa Francisco ha erigido por encima de la Curia romana obedeciendo al mandato del cónclave para reformar la Curia" ${ }^{61}$, fue recibida con amplia aprobación. Su objetivo específico es el de ayudar al Papa "en el gobierno de la Iglesia universal y de estudiar un proyecto de revisión de la Constitución Apostólica Pastor bonus sobre la Curia Romana" ${ }^{2}$. Algunas decisiones ya emanadas de allí han sido relevantes, como la Comisión de protección de menores o la reorganización y búsqueda de transparencia en las finanzas vaticanas.

Por tratarse de un organismo cuya agenda de trabajo, designación de miembros y relevancia efectiva dependen exclusivamente de la voluntad del Papa, representa un paso positivo, pero provisorio. Puede constituir el punto de partida para la formación de una institución permanente que exprese mejor la riqueza teológica de la sinodalidad de la Iglesia, la colegialidad del episcopado y el servicio del primado propio del obispo de Roma. Diversas sugerencias han sido propuestas. Ya en el Concilio Vaticano II -a partir de los debates en el aula en $1963-{ }^{63}$, y en fecha posterior, se sugirió la creación de un nuevo organismo que, junto con el Papa y como representación de las iglesias locales, tuviera la tarea de dirección y supervisión de la Curia romana en su servicio a la comunión de las iglesias. Su novedad consistiría en que pondría a la Curia no solo bajo la autoridad del Papa, sino también de la solicitud del colegio de los obispos. Dicho organismo no sería solo una ayuda al obispo de Roma en su tarea primacial, sino que constituiría también una expresión de una teología de la communio ecclesiarum (localium, regionalium) y de la

61 M. FagGioli, La onda larga del Vaticano II. Por un nuevo posconcilio (Ed. Universidad Alberto Hurtado, Santiago 2017) 157.

62 http://w2.vatican.va/content/francesco/it/letters/2013/documents/papafrancesco_20130928_chirografo-consiglio-cardinali.html

63 Cf. M. Faggioli, Il vescovo e il Concilio. Modello episcopale e aggiornamento al Vaticano II (Il Mulino, Bologna 2005) 403-406. 
especial responsabilidad que compete al episcopado como "sujeto de la suprema y plena potestad sobre la Iglesia universal" (LG 22) en unión con el sucesor de Pedro ${ }^{64}$.

No obstante todos los argumentos positivos que se aportan en relación a este posible nuevo organismo, no dejo de percibir un riesgo importante: que se consolide aún más la imagen de la Iglesia como una entidad regida desde un centro de gobierno mundial. Justamente lo contrario a la "saludable descentralización" (EG 16); una visión universalista que opaca la idea central de una Iglesia comunión de iglesias locales, in quibus et ex quibus se realiza la Iglesia católica.

(1) Uno de los aspectos más recurrentes en los diálogos en el citado seminario de 2015 en La Civiltà Cattolica fue la relación entre teología $y$ derecho, más precisamente las múltiples insuficiencias que se advierten en el código de 1983 en relación a su principal pretensión: representar una traducción canónica de las enseñanzas conciliares sobre la Iglesia. Se trata de una preocupación que comparten múltiples y calificados autores/as. En palabras de H. Legrand, el Vaticano II no se habría "preocupado de la puesta en obra efectiva de su "discurso de convicción»" ${ }^{5}$. El mismo Legrand, años después, encuentra explicable por varios motivos que la colaboración entre los teólogos y los canonistas no fuera la deseada en el tiempo del Concilio, pero destaca que "tal colaboración debería ser una prioridad para los eclesiólogos" ${ }^{\prime \prime}$. Sin una legislación práctica, escribe Myriam Wijlens, también presente en el seminario de Roma, ideas como la colegialidad, "permanecen como lo que son en los documentos: una bella intuición" ${ }^{67}$. En el mismo sentido se expresaba Sabine Demel refiriéndose específicamente al ejercicio del sensus fidei en la Iglesia: "la participación no puede dejarse abandonada a la casualidad o al juicio subjetivo de algunos. Son necesarias estructuras e institucio-

64 Cf. M. FagGioli, "Per una reforma del governo centrale di una Chiesa collegiale e sinodale a cinquant'anni del Vaticano II", en A. Spadaro - C. Galli, La reforma e le riforme, 330-346, 341ss.; L. Baldisseri, A cinquant'anni, 74, 123, 327, 333, 413.

"Quelques réflexions ecclésiologiques", 516.

"La sinodalità al Vaticano II", 107.

"Values and Canon Law", en Louvain Studies 20 (1995) 393-400, 395. Cf. M. WijLens, "Konzil und Rechtsstrukturen”, en Ökumenische Rundschau 62 (2013) 537-546. 
nes de participación aseguradas jurídicamente" 68 . Se trata de una idea elemental que, por una difundida y arraigada forma mentis e inercia institucional, es de difícil aprendizaje para la cultura eclesial. El asunto -teología y derecho- posee, además, una estrecha relación con uno de los marcos contextuales de las reflexiones en el seminario de Roma: la inculturación. Así lo advierte también en una publicación reciente, Vincenzo Mosca: "El futuro del derecho eclesial se encuentra en dar más espacio y atención al derecho particular, es decir, a su inculturación" $"$.

Ofrezco un ejemplo concreto. El llamado a aprovechar todas las posibilidades para la corresponsabilidad que ya ofrecen los organismos existentes, como lo hace de manera justa y fundada A. Borras ${ }^{70}$, es oportuno, pero insuficiente. Se precisa dar nuevos pasos concretos y creativos para reformar estructuras que todavía son muy piramidales. En la cuestión particular de la participación de los laicos y las laicas en diócesis y parroquias una medida posible podría tener lugar en la forma de una obligación personal voluntaria contraída por el obispo diocesano. En determinados casos a precisar el obispo se obligaría a sí mismo a escuchar la voz de los miembros de diversas instancias eclesiales -consejo pastoral diocesano, sínodo diocesano- $y$, eventualmente, obligarse en determinadas circunstancias a seguir el consejo del Pueblo de Dios dado de manera representativa. En cuanto único legislador en la diócesis, el obispo no puede ser coaccionado a ello por nadie, pero tampoco impedido. La renuncia a determinadas posiciones jurídicas obligándose a sí mismo voluntariamente es una posibilidad abierta a toda persona jurídica ${ }^{71}$.

68 "Vertrauen in das Wirken des Geistes. Entfaltungsräume für den Glaubenssinn der Gläubigen”, en Herder-Korrespondenz 68 (2014) 524-529, 525.

69 "Para una inculturación del derecho eclesial", en Concilium 368 (2016) 105-112, 112.

70 Cf. "Sinodalità ecclesiale, processi partecipativi e modalità decisionali. Il punto di vista di un canonista”, en A. SPADARO - C. GALLI, La reforma e le riforme, 207-232, 209. Debe tenerse en cuenta también que la distinción entre voto consultivo y voto deliberativo, aparentemente tan nítida, posee límites y no visibiliza inmediatamente los matices que se incluyen en ella. Cf. A. BORRAS, "Votum tantum consultivum. Les limites ecclésiologiques d'une formule canonique”, en Didaskalia 45 (2015) 145-162.

71 Existen ejemplos al respecto, cf. S. Demel, Zur Verantwortung berufen, 81. 


\section{REFLEXIÓN FINAL}

En buena medida, esta agenda compleja es lo que parece: un proceso de reforma "occidental" e "interno". Están en cuestión, como lo afirma Dulles en la cita aportada en la introducción, las actuales estructuras de la Iglesia, especialmente del catolicismo romano, que "tienen una impronta muy fuerte de las pasadas estructuras sociales de la sociedad europea occidental". Pero las reformas no tienen un fin en sí mismo. Su avance y resultados progresivos constituyen un presupuesto estructural ineludible para hacer frente, con una institución más evangélica, teológicamente más consistente y culturalmente más adecuada y flexible, al panorama de una iglesia mundial, a procesos de inculturación y diálogo con espacios geográficos, crecientemente importantes, donde el cristianismo es realmente marginal. En este sentido, este proceso de reforma es parte de una agenda "política": de globalización e interculturalidad, de diálogo interreligioso y trabajo por la justicia y la paz; al servicio de una Iglesia en salida misionera, que desea ofrecer el evangelio como forma de vida hasta los confines de la tierra.

Esta es la pregunta de fondo que emana de la que es, probablemente, la interpretación más citada y consensuada sobre el Vaticano II y su suerte futura:

"Las cosas están por tanto así: o la Iglesia ve y reconoce estas diferencias esenciales de las otras culturas, en el seno de las cuales debe llegar a ser Iglesia mundial, y de ese reconocimiento saca las consecuencias necesarias con audacia paulina, o bien permanece como una Iglesia occidental, a fin de cuentas, traicionando de esta manera el sentido que ha tenido el Vaticano II"72.

Es claro que las estructuras actuales, su autocomprensión y formas de ejercicio, son ampliamente deudoras del segundo milenio -europeo, occidental- de la Iglesia. Favorecida por la separación de Oriente, en Occidente se edificó una forma determinada de Iglesia católico-romana monocultural con pretensiones de universalidad. En las reformas actua-

72 K. Rahner, "Theologische Grundinterpretation des II. Vatikanischen Konzils", en Schriften zur Theologie. Band 14 (Benzinger Verlag, Einsiedeln 1980) $287-$ 302, 298. Cf. M. DE FranÇA Miranda, "Reforma ecclesiale e inculturazione della fede. La configurazione ecclesiale latinoamericana”, en A. SPADARO - C. GAlLI, La reforma e le riforme, 521-533; J.M.C. FRANCISCO, "Un trittico sull'inculturazione in Asia", en A. SPADARO - C. GALli, La reforma e le riforme, 552-568. 
les se decide si la Iglesia será en el tercer milenio lo que Rahner auguraba como lectura clave del Vaticano II: el inicio de una iglesia mundial enraizada en cada cultura y región, ya no la exportación de un determinado tipo cultural de cristianismo. En este sentido, en el paso de Benedicto a Francisco podríamos estar asistiendo a un salto cualitativo. Este camino reclama sistemáticos procesos sinodales de discernimiento; no se realiza, además, sin debates ni resistencias importantes. Con perspectiva histórica, O’Malley advierte: "Podemos tomar como axiomático que el grado de resistencia que un cambio suscita está en proporción directa a su desafío al sistema en posesión" ${ }^{3}$. Francisco habla de una "pirámide invertida"; efectivamente, hay que invertir la pirámide en las mentalidades y traducirlo en las instituciones.

73 J. O’Malley, "La reforma nella vita della Chiesa”, 88. 